\title{
Examination of animal and zoonotic pathogens using microarrays
}

\author{
Shivani OJHA, Magdalena KosTRZYNSKA* \\ Agriculture and Agri-Food Canada, Food Research Program, 93 Stone Road West, Guelph, \\ Ontario, N1G 5C9, Canada
}

(Received 12 December 2006; accepted 27 July 2007)

\begin{abstract}
The advancement in functional genomics, such as DNA microarrays along with the genome availability of important pathogens as well as of human and livestock species has allowed scientists to study the expression of thousands of genes in a single step. In the past decade, DNA arrays have been employed to study infectious processes of pathogens, in diagnostics, and to study host-pathogen interactions. The generation of enormous data sets by microarray experiments also stimulated the growth of a new generation of analytical software. The information provided by microarray experiments has been useful in generating new hypotheses for future research. The concept of DNA array technology has been utilized in the development of novel diagnostic methods. This review highlights the application of microarrays in the field of veterinary research.
\end{abstract}

microarray / detection / host-pathogen interactions / zoonotic

\section{Table of contents}

1. Introduction

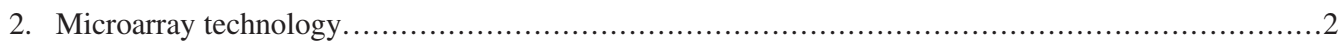

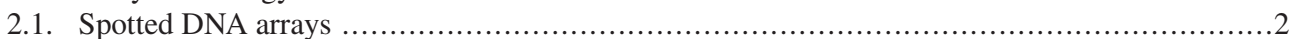

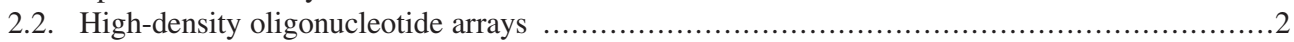

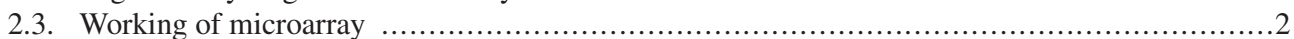

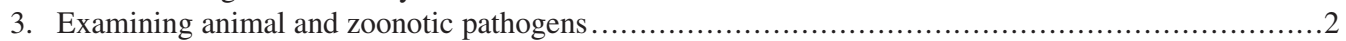

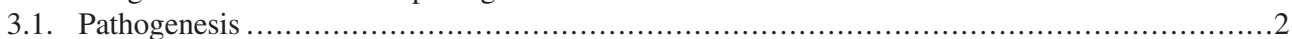

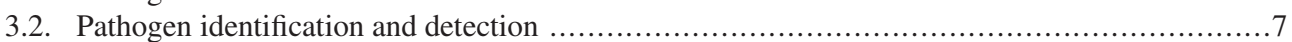

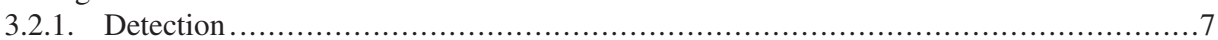

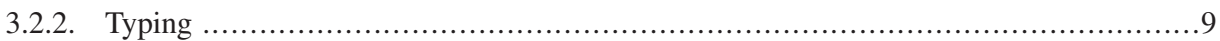

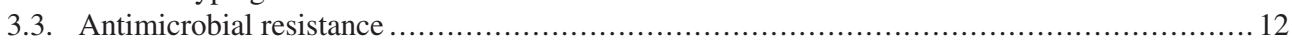

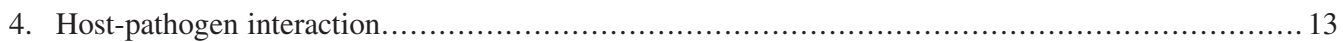

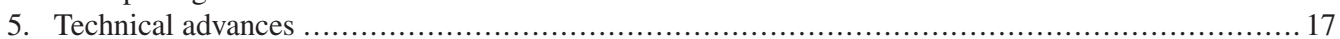

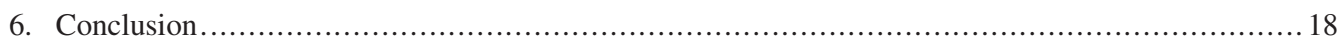

\section{INTRODUCTION}

While the majority of microbes causing disease in vertebrates were discovered in the past century, in the last few years the focus has been on understanding the mechanism of pathogenesis and establishing the principles of infec-

\footnotetext{
* Corresponding author: kostrzynskam@agr.gc.ca
}

tion. The characteristic feature of pathogenic microorganisms is their ability to cause tissue damage thereby causing disease in their host. The process involves several stages of cell-cell interactions from the adhesion of the infectious agents to the invasion of the host tissues simultaneously evading the host's immune responses. For decades, researchers have used 
a wide variety of conventional and molecular methods to study virulence determinants and mechanisms of pathogens and the mechanisms of host immune response. This information has been utilized in the design of safe and effective vaccines, diagnostics, and therapeutics. The availability of the human genome, together with genomes of many livestock species, laboratory animals as well as genome sequencing of many important pathogens has offered new opportunities for exploring molecular mechanisms of infection. DNA microarray technology has gained rapid acceptance in a variety of fields for studying the roles of genes in a particular condition.

In this paper, the studies that employed microarrays in examining mainly animal and zoonotic pathogens will be reviewed. The application of DNA microarray in unravelling virulence determinants, gene functions, pharmacogenomics, genotyping, diagnostics, and finally the use of DNA arrays in the investigation of host-pathogen interactions will be discussed.

\section{MICROARRAY TECHNOLOGY}

DNA microarrays work on the well known principle of nucleic acid hybridization allowing for the parallel detection and analysis of the patterns of expression of thousands of genes in a single experiment. A DNA microarray is a solid microscopic checkerboard of thousands of different DNA sequences (from either the host or the pathogen) physically attached to a silicon wafer or glass slide [16]. The two most commonly used microarrays are the following: spotted DNA and high-density oligonucleotide arrays.

\subsection{Spotted DNA arrays}

In this array, a single-stranded or dissociated double-stranded DNA is attached to a glass slide. The DNA can be produced from a cloned or PCR amplified target. The DNA at each spot is $\sim 300-800$ nucleotides long. Synthetic oligonucleotides (18-70 nt long) are also commonly used for spotting arrays. The method is relatively cost effective, flexible, can be produced in house, and is widely used in academic settings [52].

\subsection{High-density oligonucleotide arrays}

These are constructed by synthesizing $\sim 18$ to 70 nucleotides in situ on a solid substrate using a photolithographic manufacturing process, thus avoiding the need for attachment methods. These are available commercially. The slide has several different oligonucleotide sequences from the same gene. This technique produces more authentic results since the same gene is probed many times in the same experiment.

\subsection{Working of microarray}

In gene expression experiments, mRNA samples are reverse transcribed to cDNA and are fluorescently labelled either during a reverse transcription reaction or later. The two samples, typically a "test" and a "control" are differentially labelled with fluorochrome dyes Cy5 (red) and Cy3 (green). The two samples (fluorescently labelled targets) are incubated with the DNA probes on the microarray slide. The target, if complementary, hybridizes with sensitivity and specificity to the DNA probe. The slide is scanned and the ratio of intensity of red and green fluorescence at each spot hybridized with Cy5 and Cy3 labelled DNA is quantitated [16].

In genomic profiling experiments, DNA extracted from a biological sample is fluorescently labelled and hybridized to the microarray. Alternatively, sample DNA is amplified by PCR, labelled by fluorescence and hybridized to the array. More technical details about microarrays can be found in previous reviews $[16,30,52]$.

\section{EXAMINING ANIMAL AND ZOONOTIC PATHOGENS}

Microarrays have been widely employed to interrogate gene expression profiles of many important human pathogens but so far relatively fewer studies are found on pathogens of veterinary importance. In the following sections, application of DNA microarrays in global gene profiling of animal and zoonotic pathogens as well as in the study of pathogenicity, for diagnostics development, in epidemiological studies, and pharmacogenomics will be examined. 


\subsection{Pathogenesis}

Pathogens adapt rapidly to a changing environment whether outside or within the host. This adaptation is through the regulation of expression of several genes, including virulence genes, to the changing stimuli, and microarrays allow global analysis of such gene expression simultaneously under a particular condition. The DNA array experiments require careful design considering the following: (i) the relative levels of mRNA change rapidly in response to changing stimuli and (ii) relative mRNA levels depend on the rates of transcription and mRNA turnover (iii) obtaining prokaryotic mRNA from eukaryotic tissues. The shape of the array experiment is generally a two-condition design, for example, comparison of transcripts of treated versus untreated and wild type versus mutant strains. In addition, sampling experiments that reflect the time course of genetic responses are also employed. The following section discusses the application of DNA arrays for studying virulence and adaptation associated with gene expression of pathogens (Tab. I). The in vivo growth or the conditions mimicking host tissues generate transcriptomes containing transcripts of virulence determinants along with those essential for in vivo survival, including metabolic genes and nutrient procurement genes, which indicate essential survival genes that could be dispensable in the growth medium.

Salmonella enterica serotypes are widely associated with diseases of both humans and animals. The chronic carriage of facultative intracellular Salmonella is the major cause in the spread of disease, however, the mechanism of persistence of the organism is poorly understood. Using a DNA microarray of S. enterica serovar Typhimurium LT2 genome, the transcriptomes of the wild type and a mutant carrying point mutation in the polynucleotide phosphorylase (PNPase) gene were analysed. The point mutation in PNPase affected invasion genes in Salmonella Pathogenicity Island (SPI 1) and genes involved in intracellular growth of the organism in SPI 2, thereby prolonging the survival of pathogen in mice [27]. The study demonstrated alterations in global regulator, PNPase as a key element of viru- lence and persistency of Salmonella. The role of another global regulator, $\operatorname{csr} A$ in virulence of S. enterica Typhimurium was found in a similar study [59]. Recent analyses of gene expression of double murein lipoprotein mutant of the pathogen revealed alterations in the expression of flagellar, invasion, and virulence gene regulators in the mutant compared to the parent strain. The gene expression data were in agreement with the non invasive and attenuated phenotype of the mutant strain [39].

The microarray experimental design of comparing transcripts of treated versus untreated or the evaluation of transcripts of microbes under two different conditions is a powerful approach for studying differential gene expression. The transcriptome of intramacrophage $S$. enterica Typhi and $S$. Typhimurium were pathogens studied recently by Faucher et al. [40]. The study revealed that the differential expression of various genes involved in the intracellular survival of the pathogen, for example, increases transcripts of those encoding resistance to antimicrobial peptides, whereas the flagellar apparatus, chemotaxis, and iron transport genes are downregulated. Few studies aiming at transcript analysis of bacteria associated with eukaryotic cells have been done. The factors that limit such investigations are the following: low bacterial recovery from the host, short halflife of bacterial mRNA, and contamination of bacterial mRNA with the host RNA. Selective capture of transcribed sequences (SCOTS) was applied in this study to obtain high quality bacterial RNA from the intracellular niche. The technique utilizes a selective hybridization to bacterial genomic DNA to separate bacterial RNA from the host's cDNA. In order to identify genes of $S$. enterica Typhimurium essential for survival and replication within mouse macrophages in vitro as well as in mice spleens, Salmonella cDNA microarray was employed to track signature-tagged transposon mutants of the pathogen [25]. This novel strategy of combining signature-tagged transposon mutagenesis and microarrays could identify mutants deficient in survival in cultured macrophages and identify components of SPI 2. The results were in conformity with 


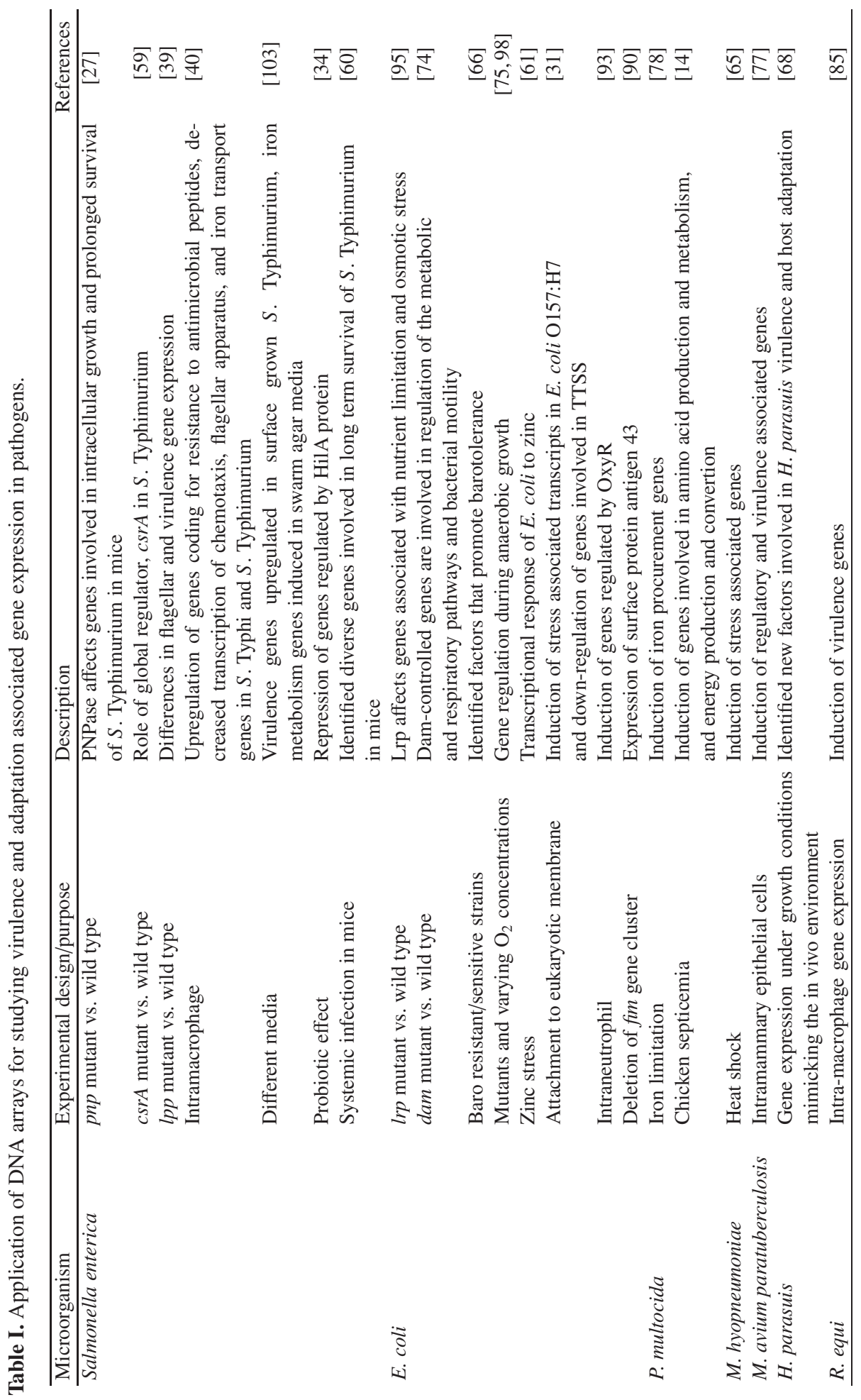


those of original STM screens, thus highlighting the utility of the DNA array approach for high throughput screening of virulence genes. A similar microarray-based negative selection approach using a mutagenized library of S. enterica Typhimurium was used to identify Salmonella genes required for prolonged systemic infection in the mouse model [60].

Since the microarray approach is advantageous in parallel to the study of physiology of microbes grown in a particular environment, the gene expressions of $S$. enterica Typhimurium during swarming and those grown in liquid and solid media were analysed [103]. The large numbers of virulence associated genes were up-regulated in surface grown bacteria, while iron metabolism was largely induced in swarm agar media. The study also identified new genes involved in virulence and motility of the pathogen. In order to identify regulatory motifs of virulence of $S$. enterica Typhimurium, the transcriptome of Salmonella grown in the presence of culture supernatant of the probiotic, Lactobacillus rhamnosus GG was analysed. The microarray data indicated repression of a cluster of genes known to be regulated by the HilA protein, including the HilA box in the promoter region [34].

The microarray approach is also widely applied to study the pathogenesis and physiology of Escherichia coli. E. coli inhabits the intestinal tract of warm blooded animals, most of which are harmless. However, various strains are pathogenic to both humans and animals. The incidence of E. coli $\mathrm{O} 157: \mathrm{H} 7$ in food animals and its low infective dose are major public health concern. During processing, the meat is subject to varying degrees of pressure in order to get rid of the contaminating pathogen. In a study, DNA array analysis of pressure resistant and sensitive E. coli O157:H7 strains subjected to various degrees of pressure showed an effect on transcription of many genes involved in the physiology of the pathogen [66]. The genes affected included the ones involved in stress response, the thioldisulfide redox system, Fe-S cluster assembly, and spontaneous mutation. The baroregulated mutants of the pathogens were further anal- ysed to show that the sigma factor, lipoprotein, thioredoxin, and a DNA-binding protein are promoters of barotolerance.

Within the host body, E. coli is exposed to various oxygen concentrations where it adapts to changing environmental cues. The transcripts of wild type $E$. coli and various mutants grown under aerobic or anaerobic conditions were analysed. Such global analyses enable scientists to understand the adaptation strategy of the pathogen under various conditions [75]. The whole genome screen of transposon mutagenized $E$. coli grown under aerobic and anaerobic conditions was conducted through microarray to identify conditionally essential genes [98]. Metal cations play an important role in the physiology of a microbe, synthesis of polysaccharide, and sensitivity to antibiotics. Zinc is an essential trace element, vital in cell biology. The global gene expression of $E$. coli in response to toxic and sublethal concentrations of zinc was studied [61]. The zinc stress repressed acid stress genes, while genes involved in cell structure, multi drug resistance efflux system, transport, sensors and regulators were upregulated. The findings demonstrate the role of metal ions in the modulation of antibiotic resistance among pathogens. Among many components, the adhesion of E. coli is also mediated by fimbriae. The molecular events in response to fimbrial gene expression in E. coli K-12 were explored using high-resolution oligonucleotide arrays. A differential expression of fim genes was observed, while deletion of the fim gene cluster led to the expression of surface protein antigen 43 [90]. Another study demonstrated differential expression of E. coli $\mathrm{O} 157$ genes attached to the plasma membrane of red blood cells [31]. The stress-associated mRNA increased, while levels of mRNA involved in the type III secretion system were decreased.

Bacterial growth within the host tissues is limited by nutrient availability that does not support long periods of exponential growth. It is thought that the leucine response regulatory protein (Lrp) plays an important role in the stationary phase of E. coli. To elucidate the role of $\operatorname{Lrp}$ in $E$. coli, microarray analysis of isogenic Lrp+ and Lrp- strains 
was done. The study found numerous genes regulated by Lrp, including those responsive to nutrient limitation, high concentration of metabolites, and osmotic stress [95]. Another study assessed the transcriptome of wild type and Dam mutant strain of E. coli grown under various conditions [74]. Many virulenceassociated genes were repressed in mutant cells, while stress response genes and genes of amino acid metabolism were expressed at higher levels. The global analyses confirmed and suggest the role of Dam mediated methylation in global regulation of genes. The circumvention of host defences is crucial to the pathogenesis. To study the bacterial response within a human neutrophil phagosome, Staudinger et al. [93] employed a DNA array of more than $4000 \mathrm{E}$. coli genes for the experiment that demonstrated that the ingestion of $E$. coli by neutrophils induced expression of genes regulated by oxidase-sensing transcription factor, OxyR.

Global gene profiling of Pasteurella multocida grown in vitro as well as those obtained from in vivo challenge experiments has been studied. P. multocida is the etiological agent of a range of diseases in avian and variety of mammalian hosts. Iron is an important element of cellular biology and is part of many apoenzymes. It is known that limitation of the availability of free iron within the host body affects the virulence gene expression of the pathogen. In order to understand a genome wide picture of gene expression of $P$. multocida in response to low iron, a whole genome microarray experiment was conducted. The study showed that genes of energy metabolism were repressed, while those involved in iron binding and transport increased up to 2.1 to 7.7-fold. Significantly differentially expressed genes of unknown functions were also identified [78]. The transcriptional response of P. multocida during natural infection in the chicken was also studied. The expression profiles of bacteria obtained from the blood of septicemic chickens were compared with those grown in a rich medium in vitro. The majority of upregulated genes were highly expressed genes of energy metabolism required for survival within the host tissues, whereas un- knowns and the ones known with poorly characterized functions were identified as down regulated genes. The expression profiles of many genes were similar with those observed during growth under iron-limiting conditions [14]. Microarray analyses of Haemophilus parasuis, another member of family Pasteurellaceae was carried out in vitro under conditions mimicking - an in vivo environment of swine. The kinetics of mRNA transcripts of the swine pathogen grown under various conditions was evaluated at various time points. Since the genome of $H$. parasuis has not been sequenced, the microarray of 6000 amplified clones was generated. Many metabolic, transport genes, and virulence gene homologs were found to be involved in the adaptation of the pathogen under different conditions [68].

Mycoplasma hyopneumoniae colonizes the swine respiratory epithelium and causes pneumonia that predisposes the animal to secondary infections. In order to understand the progression of disease within the respiratory tract of the host, M. hyopneumoniae was subjected to a temperature shift in vitro mimicking similar swings as in swine. The expression of genes was scanned on a microarray slide harboring 632 open reading frames of the pathogen. To enhance sensitivity, a hexamer primer set was used to generate cDNA from mRNA. The study identified genes with a significant difference in expression to heat shock conditions [65].

It is thought that M. avium subsp. paratuberculosis infects young calves by crossing the intestinal barrier. The pathogen is also known to infect the mammary gland and can survive in milk. The current study showed enhanced invasion of bovine kidney cells by the pathogens that were initially residing within mammary epithelial cells and the ones exposed to milk. To determine expression levels of M. avium subsp. paratuberculosis during intracellular survival within mammary epithelial cells (MAC-T), DNA array analysis was undertaken. The transcripts from $24 \mathrm{~h}$ MAC-T cells infected with $M$. avium subsp. paratuberculosis were hybridized to the array of the pathogen. A variety of genes were found to be upregulated, including regulatory 
genes, metabolic, and virulence-associated genes [77]. The enhanced ability to invade was thought likely due to the hyperosmolar conditions in milk that might trigger expression of invasion-related genes. The expression patterns of Rhodococcus equi, an equine pathogen that resides within macrophages during the infectious process were examined using a spot-based microarray of virulence genes of the pathogen. A variety of virulence associated genes were induced in macrophage growing $R$. equi. In addition to virulence plasmid genes, the study identified chromosomal virulence genes induced within equine macrophages [85].

Technical issues of procuring enough bacteria and purity of RNA from host tissues limit accurate in vivo transcriptional profiling experiments, although few studies demonstrate in vivo experiments with human pathogens, for example, use of dialysis chambers implanted in the peritoneal cavity of the rat to analyse transcriptome of Borrelia burgdorferi, the etiological agent of Lyme disease [88] and recently, intramacrophage $S$. enterica Typhi and $S$. Typhimurium transcriptomes [40], and transcripts of P. multocida from septicemic chickens were studied as well [14]. The final processed sample lacking host cells and any commensal flora is advantageous for studying in vivo expressed transcripts of the pathogen. In vivo microarray studies of animal and zoonotic pathogens could explain the complex interactions involved in pathogenesis, for example, polyserositis causing $H$. parasuis expression profile in synovial fluid of the pig, transcriptome of E. coli $\mathrm{O} 157$ in the initial colonization of the intestinal tract of cattle etc.

\subsection{Pathogen identification and detection}

DNA microarrays offer a device to interrogate DNA sequences of the target sample for the detection and identification of pathogens concerned with public health and veterinary diagnostics (Tab. II). Such genomic analysis also permits epidemiological investigation, forensic application, and genotyping of the pathogen for polymorphism detection. Depending on the source of the sample, for example, from livestock farm environmental samples, water, food samples, and clinical samples from mammalian hosts, the processing of sample and nucleic acid purification is a major challenge for a proper hybridization step and detection. These samples usually carry various biological extracts/tissues that contaminate nucleic acid with inhibitors during purification, which can limit fluorescent reporters. It has been emphasized that the final detection by microarrays is of minimal use if the initial critical steps encounter marked difficulties with the processing of a sample [20]. The microarray tool has been utilized for determining the presence or absence of a pathogen, identifying the pathotype, however like any other genome-based method, inference about the viability and enumeration of the organism is difficult.

\subsubsection{Detection}

Since Salmonella spp. are important pathogens of food animals, rapid and sensitive detection is desired. A fiber-optic DNA microarray carrying oligonucleotide invA and $s p v B$ gene probes specific for Salmonella was developed. Hybridization of the probe with the target Salmonella was optimized and visualized using Cy3-labeled secondary probes in a sandwich assay. The study suggests its detection limit of $10^{3}$ to $10^{4} \mathrm{cfu} / \mathrm{mL}$ of the target pathogen at $1 \mathrm{~h}$ post hybridization with no cross hybridization with other common pathogens [2]. In order to refine the detection of Salmonella strains at subspecies level, subtractive hybridization was used to isolate unique genomic signatures of nine Salmonella strains, which were validated by microarray analysis [7]. The results of this study suggested that a large group of genes subtracted could be used together as a single probe for detecting a microbial species from complex samples. There is a steady increase in the number of published reports on biosensors and microarray techniques aiming at Salmonella detection. A rapid array-based biosensor was designed to detect serovar Typhimurium through fluorescent reporters of surface bound immunocomplexes present in the array. Various approaches aimed at the 


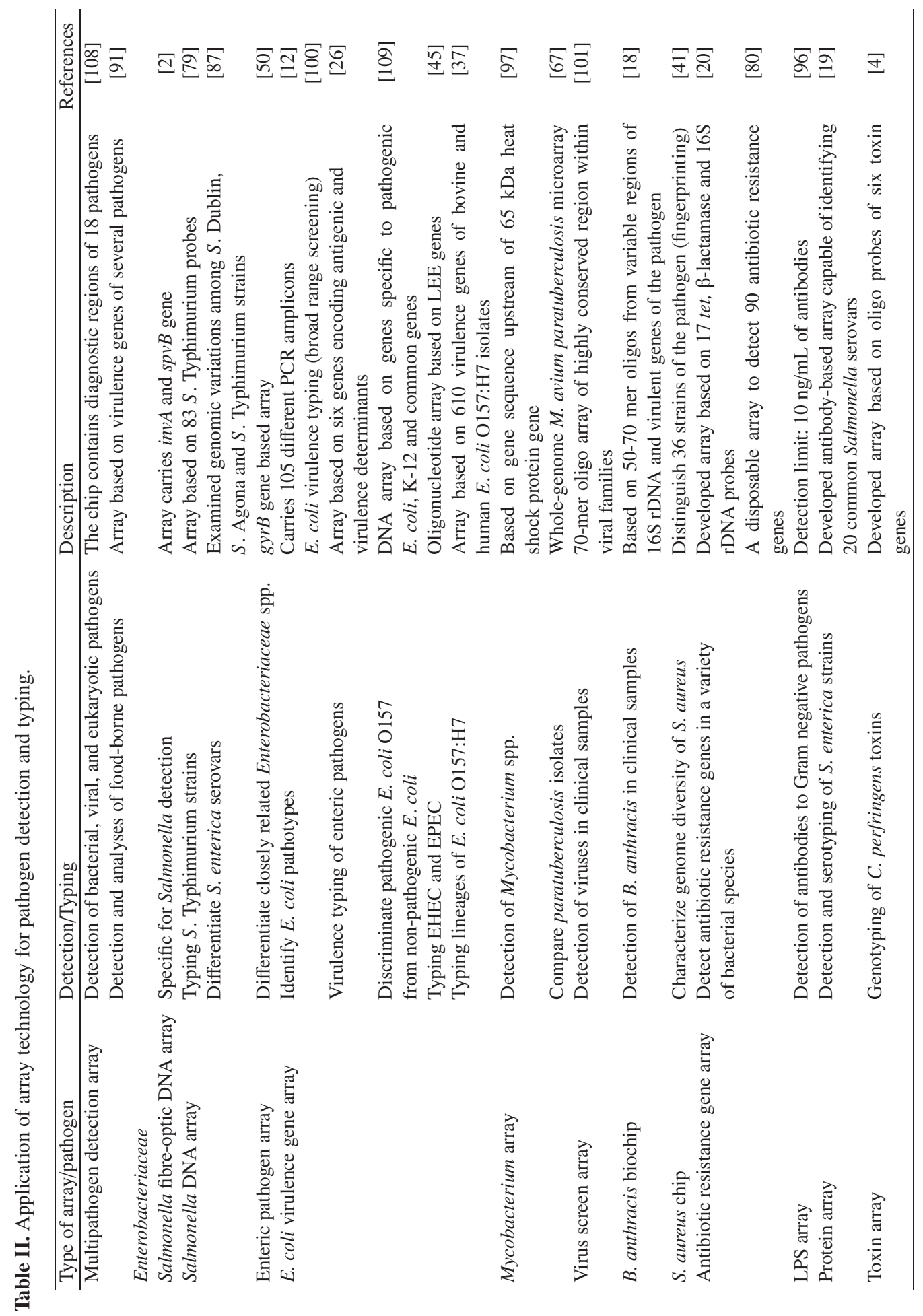


detection of salmonellae are discussed by Goldschmidt [46].

The efficiency of a nucleic acid chip carrying 25-30 mer oligonucleotide probes of four loci of E. coli $\mathrm{O} 157$ was examined for the detection of pathogen. The array harbored four virulence loci, the intimin, Stx toxin I and II, and hemolysin A. The array was found to be 32-fold more sensitive than detecting PCR products by gel electrophoresis. In addition, the array could genotype E. coli strains [21]. The utility of DNA arrays aimed at detection and identification of food borne pathogens has been reviewed recently [58].

A diagnostic array targeting virulence genes of multiple pathogens, including Staphylococcus aureus enterotoxin genes and Clostridium perfringens toxin genes was developed [91]. In this system, redundancy of genes and of oligoprobes for a specific gene and quality control probes were incorporated to improve microarray-based detection of pathogens.

A detection method was developed using real-time PCR and DNA microarray based on the region upstream of the $65 \mathrm{kDa}$ heat shock protein of Mycobacterium spp. The results of the study suggest that the approach can be utilized for rapid identification of different mycobacterial spp. with a possibility of detection from mixed infections [97].

In recent years, the generation of chips aimed at the detection of multiple pathogens using a single platform has been increasing. A multi pathogen identification microarray for 18 pathogenic prokaryotes, eukaryotes, and viruses was developed by Wilson et al. [108]. The chip comprised of diagnostic regions of various pathogens and could identify pathogens in samples with high specificity.

A method for parallel screening of a large number of viruses was developed to facilitate comprehensive and unbiased detection of virus prevalence in a biological sample. A long oligonucleotide (70 mer) DNA microarray was generated using highly conserved regions within viral families. The chip can be utilized for virus detection and emerging new viruses in a single assay [101]. A cDNA microarray detection device for porcine reproductive and respiratory syndrome virus (PRRS) and foot and mouth disease virus (FMD) was developed [63]. The PRRS virus is a major problem in swine farms, while the FMD virus is reemerging owing to international trade. Two long sequences from PRRS and one from FMD virus were selected and spotted on a nylon membrane. The chip demonstrated rapid and accurate detection of specific genes.

Bacillus anthracis is a zoonotic pathogen and is thought to be an important agent of bioterrorism, therefore, its detection and identification is important. Burton et al. [18] developed a biochip to specifically detect and differentiate $B$. anthracis from other bacteria in a clinical sample. The array includes 50-70 mer oligonucleotides from variable regions of $16 \mathrm{~S}$ rRNA genes as well as few virulent genes of the pathogen. Since assays must be capable of reporting the results within a reasonable time frame in a diagnostic lab, a hybridization time course of $1-2 \mathrm{~h}$ was found to be optimal for detecting signals in this microarray assay with sensitivity similar to PCR when specific primers were used.

\subsubsection{Typing}

Pathogenic microorganisms are versatile in their ability to adapt and colonize diverse ecological sites within the host. This characteristic of adaptability to survive under various conditions is mainly due to regulation of gene content and allelic variations among strains. Within the past decade, whole genome DNA microarrays have been widely used to index diversity in chromosomes of bacterial species, which has contributed towards taxonomic assignments, identification of new emerging species/strains, and understanding evolutionary relationships among bacterial species.

The data of microarray analysis of genomes of 13 variants of the tuberculosis vaccine strain, bacillus Calmette-Guerin and the laboratory strain, M. tuberculosis $\mathrm{H} 37 \mathrm{Rv}$ indicate evolution of the vaccine strain, which emphasizes the development of improved vaccine and diagnostics for the organism [11]. Analyses of the array experiment indicated deletion of transcriptional regulatory regions of 
virulence expression from the vaccine strain. In addition, TB DNA microarray representing genes of $\mathrm{H} 37 \mathrm{Rv}$ was employed to detect polymorphisms among $M$. tuberculosis isolates [36]. The hybridization results of 15 M. tuberculosis strains obtained from two different geographical regions and the reference strain H37Rv showed genetic variability. Highly polymorphic DNA sequences were in non-essential genes of the bacterium [36]. Microarray based comparison of three $M$. avium avium subsp. paratuberculosis isolates, one sheep, and two cattle strains revealed three large genomic deletions in the sheep strain. Such deletions and variations in genes of closely related species explain differences in host specificity and pathogenicity [67].

Staphylococcus aureus is an important human pathogen that causes fatal septicemia, endocarditis, and toxic shock. It is also an economically important pathogen of livestock, causing mastitis in cows and sheep. The increasing antibiotic resistance of the pathogen has led to treatment failures. A DNA microarray was used to characterize genomic diversity, evolution, and virulence gene distribution among 36 strains of $S$. aureus [41]. A tremendous genetic variation was found with $\sim 22 \%$ of dispensable genetic material in the genome. Amongst the 18 large regions, 10 variable regions carried putative virulence-associated genes or antibiotic resistance genes. It was inferred that horizontal gene transfer has played an important role in the evolution of $S$. $a u$ reus and that the mec gene responsible for methicillin resistance has been transferred into various $S$. aureus chromosomal backgrounds at least five times. The clonal lineage of $S$. $a u$ reus associated with bovine mastitis was found to be closely related to the ovine strains.

Numerous molecular methods have been used to detect and identify pathogenic $E$. coli strains, such as DNA-DNA hybridization, PCR, and multiplex PCR. However, these approaches have limitations that likely generate false results because most $E$. coli strains share a number of virulence genes. Microarray permits rapid and specific detection of the presence/absence of a large number of virulence genes within a given $E$. coli strain. To iden- tify pathotypes of $E$. coli, a virulence gene DNA microarray composed of 105 PCR amplicons representing different virulent strains of E. coli was designed [12]. This virulence chip was optimized and validated with known samples and pathotype assessment in clinical samples was found to be rapid and specific. The microarray was found to be useful in distinguishing phylogenetic groups of genes among E. coli strains. These studies suggest the utility of microarray in detection of virulence genes acquired horizontally as well as in the identification of emerging pathotypes. In clinical diagnostics, pathogens are identified using biochemical and immunological markers. These conventional approaches are often time consuming and do not directly characterize virulence markers of the pathogen identified. The virulence gene array of $E$. coli containing virulence genes was designed for the automated identification and characterization of $E$. coli and other enteric pathogens in a single test procedure $[26,45,56,100]$.

Similarly, a DNA array to discriminate pathogenic E. coli O157 from non-pathogenic E. coli strains was developed. The array could successfully confirm strain genotypes while detecting antibiotic resistance genes at the same time [109]. DNA array technology was further applied to test lineages of $E$. coli O157:H7 in another study. It is known that clinical isolates of the pathogen are clustered in two separate lineages. To examine if the virulence genes are differentially expressed between the two lineages, microarray was used for initial screening. Significantly different expression of 73 genes was revealed using 610 virulence genes of the two lineages, the human and bovine clinical isolates. The results of the experiment gave insight into differential regulation of virulence genes among isolates of diverse hosts and provide a basis for generating hypotheses for future studies [37].

S. enterica serovars Enteritidis and Typhimurium are among the most common cause of food-borne infections in developed countries. The typing of epidemic Salmonella strains is important in epidemiology; serotyping and phage typing are routinely done in diagnostic laboratories. A DNA microarray 
was devised for the differentiation of serovar Typhimurium. The chip consists of 83 serovar Typhimurium probes obtained by subtractive hybridization and from a public database. The array could distinguish Typhimurium strains and identify distinct groups among thirteen Typhimurium DT104 strains [79]. Such specific arrays harboring small numbers of selected probes are useful typing devices, especially where certain known pathotypes are endemic.

Genomic variations among 12 environmental, veterinary, and medical $S$. enterica serovars were evaluated using Salmonella DNA array. Limited intraserovar diversity was established although the serovars tested had extensive geographic and source differences [87]. The DNA array has been a powerful approach for genomic comparisons of many important pathogens [15,22, 24,44,81]. A high level of gene gain or loss was revealed in all the lineages of $S$. enterica and $S$. bongori, which is thought to be an event of lateral transitions of genetic material [84]. DNA microarray based genotyping has been extensively applied to Salmonella spp., which are useful in updating phylogenetics and epidemiological investigations [6, 23, 69, 83].

Many Gram negative bacteria are important pathogens of both humans and animals, and their specific diagnosis is desired for proper treatment. The concept of microarray technology was utilized to generate "lipopolysaccharide (LPS) array" for the detection of Gram negative bacteria. The outer membrane of Gram negative bacteria is composed of unique LPS molecules that are immunogenic and are species/strain specific. Since anti-LPS antibodies in clinical samples are of diagnostic value, the LPS array was evaluated in the specific diagnosis of certain Gram negative pathogens. In this study, LPS was spotted on nitrocellulose coated glass slides where epitopes were intact and accessible [96]. Monoclonal antibodies specific for E. coli O111, E. coli O157, Francisella tularensis, and S. enterica serovar Typhimurium $\mathrm{O}$ antigens were used to evaluate the assay. The detection limit of antibodies was reported to be $10 \mathrm{ng} / \mathrm{mL}$, which is 100 -fold more sensitive than con- ventional immunofluorescence assays. Using LPS arrays, canine serum samples positive for tularaemia could be differentiated from the negative samples. Further refinements of such arrays could find place in diagnostics and seroepidemiology.

One study developed a novel "protein array" based on the Kauffmann-White scheme for serotyping $S$. enterica strains. The array harbored 35 antibodies capable of identifying 20 commmon Salmonella serovars [19]. Such novel assays based on the concept of microarrays provide flexibility of options for developing specific methods, which are especially useful in clinical diagnostics where pathogenic strains are often found to be emerging or re-emerging.

Examining the microbial diversity in environmental and biological samples is challenging in terms of both specificity and sensitivity. A recent study utilized long 70-mer oligonucleotide probes targeting invA (invasion protein) and $\operatorname{sop} B$ (outer membrane protein B) genes and a positive control targeting $16 \mathrm{~S}$ rDNA of Enterobacteriaceae for Salmonella detection. Using stringent experimental conditions, a clear signal corresponding to $1 \%$ of the target organism $S$. enterica serovar Senftenberg within a mixed community could be identified and reproduced with specificity and sensitivity. The assay involved long sequence probes with the usual labeling method that proved efficient at detecting the pathogen with low input DNA, which is usually the case in clinical samples [57].

Since 16S rRNA genes cannot distinguish closely related bacteria, the gyrB gene that encodes subunit B of DNA gyrase was used in a microarray assay to discriminate between closely related members of Enterobacteriaceae [50]. Many such DNA chip methodologies have been used for measuring genetic relatedness of the members of Enterobacteriaceae and typing of related bacteria [5, 82].

The technological advances in a microarray-based test have fuelled progress in the discovery of new emerging pathogens using a single platform. A DNA microarray based tool for the identification of novel viruses is designed that can detect a wide 
range of known viruses as well as unknown emerging strains of existing viral families [102]. This array consists of highly conserved 70 mer sequence from every sequenced reference viral genome. The chip enabled the identification of an unsuspected SARS pathogen to be a virus belonging to the coronavirus family. This and many other multipathogen detection arrays demonstrate the strength of detecting novel pathogens in a single step.

Brucella species are zoonotic pathogens leading to brucellosis, which causes abortion in animals and Malta fever in humans. Since limited genome diversity exists among $\mathrm{Bru}$ cella spp., a DNA microarray based approach was employed to compare genome diversity governing host specificity and virulence of the pathogen and for this a microarray chip was constructed using the genome of $B$. melitensis, a human pathogen. Hybridization of genomic DNA of various Brucella spp. revealed alteration in 217 open reading frames. The altered sequences thus examined showed the possibility of horizontal transfer; deletions of genetic content in a particular species were found to be conserved in all the strains of that species. These findings suggest that loss or gain of genes is likely related to the host specificity and virulence determination [86]. A similar study was conducted on the Bordetella species. The Bordetella species are host specific that cause respiratory disease in both humans and animals. Although the three species are genetically closely related, differences for host specificity and pathogenicity exist. In order to examine the differences in virulence and host specificity, microarray based comparative genome hybridization coupled with suppressive subtractive hybridization was employed [29]. For this study, PCR amplified probes from the three bordetellae were spotted on a glass slide and hybridized with the genomic DNA of 42 Bordetella strains. The key gene sequence differences between the species were determined. It was found that $B$. pertussis and $B$. parapertussis are significantly different from $B$. bronchiseptica by species-specific regions related to surface structure, including the LPS $\mathrm{O}$ antigen, which might be impor- tant in host specificity. The sequence diversity at various surface protein structure loci was found to also include the fimbrial major subunit gene, fim2. This study highlighted gene loss as the principal factor in the evolution of bordetellae.

Clostridium perfringens is an anaerobe that produces several characteristic toxins that are responsible for food poisoning, especially in canned food where strict anaerobic condition prevails. The detection of toxins in the biological samples is important to confirm food safety. For rapid screening of the toxin genes, a "toxin array" comprising of oligoprobes of six toxin genes was developed and validated [4]. The array is suggested to be useful in routine testing for food safety assurance. A similar kind of "specific gene" arrays can be designed to detect pathogens in clinical samples.

Foot and mouth disease is an acute vesicular disease of cloven-hoofed animals, including ruminants, swine, and wild species. Seven different serotypes of foot and mouth disease virus (FMDV) exist and the FMD infected animals shed virus in large numbers that spread rapidly. Because of growing international trade, FMDV is recognized as a foreign animal infectious agent whose rapid detection is important. A microarray based chip comprising 155, 35-45 bp long oligonucleotide probes common among virus and serotype specific was developed for the detection and typing of the virus [10]. Using the chip, a total of 23 different FMDV strains representing all seven serotypes could be detected. The chip can be useful in early detection and typing of the virus in routine diagnostics as well as during an outbreak. The use of custom designed Affymetrix resequencing respiratory pathogen microarray was used for the simultaneous detection of respiratory pathogens from clinical samples [62]. The study could successfully identify correct species and strain levels of adenovirus and influenza virus from clinical samples.

Because of the high throughput screening of a large number of genes with sensitivity and specificity and high resolution differentiation between closely related microorganisms, the DNA array approach has important application 
in forensics; for example, cross examining pathogens in microbial forensics. In a study, large numbers of $S$. enterica isolates were fingerprinted and most pairs were found to be distinct [106]. For forensic applications of such kind, comparison of fingerprints of clinical isolates should be made against a standard list of reference strains.

\subsection{Antimicrobial resistance}

The advancement in molecular techniques has revolutionized the process of drug discovery. The pressure on pharmaceuticals is increasing due to a rise in antibiotic resistance bacteria and there is an increased demand for rapid identification of new effective targets. Microarrays are a potentially powerful device for investigating the mechanism of drug action. Studies have examined effects of drugs on expression in yeast as a model system [33]. DNA array use can thus be expanded to monitor gene expression in response to drug treatment and to identify appropriate targets for therapeutic interventions.

The rising antibiotic resistance among clinical and environmental pathogens is a major public health concern. Many different mechanisms are responsible for antimicrobial resistance but the two major genetic events responsible for it are the following: the mutation of the wild type gene to resistant alleles and the acquisition of laterally transferred genes either within the chromosome or plasmid [42]. The resistance to antibiotics leads to treatment failures and currently is a major challenge to the medical, veterinary, and pharmaceutical community. In many countries, government programs for the surveillance of resistance clones in medicine and agriculture are implemented. Identification methods are limited to PCR and Southern blotting, which are time consuming and can detect few genes at a time [42]. A microarray suitable for detecting multiple tetracycline (tet) resistance genes was developed [20]. The array carried tet genes, $\beta$-lactamase gene, and a 16S rDNA gene for E. coli. The array could identify tet genes from many test strains and excluded those not carrying any resistant gene. Similarly, specific antibiotic gene arrays were generated to detect resistance genes in Gram positive bacteria [80] and Salmonella serovars [99]. Recently, Frye et al. [42] developed an oligonucleotide array for high throughput genotyping of antibiotic resistance genes. This ninety-four resistant gene array could assay diverse bacteria, both Gram positive and negative.

A recent study by $\mathrm{Fu}$ et al. [43] examined the Affymetrix array system for monitoring drug induced gene expression in M. tuberculosis in response to isoniazid and ethionamide and conducted cross-platform analysis of related studies.

\section{HOST-PATHOGEN INTERACTION}

During an infectious process, complex interaction between the host and pathogen occurs. Probing gene expression of the host tissues and pathogen at specific stages could help us understand the interactions at the molecular level. This can permit identification of virulence-associated microbial genes and defence responses of the host tissues simultaneously. Such studies could guide towards classification of microbes based on their gene induction patterns within the host that will likely aid in the diagnosis and treatment of diseases as well as for generating new medical tools.

While cell culture and organ culture models that have been used extensively to study the interaction of pathogen with the host cells provide information about limited events, microarray scans whole gene expression during a single event $[1,107]$. Over the past five years, many research groups have employed DNA arrays to analyze host gene expressions in the presence of pathogens in both human and livestock species, however, work examining simultaneous response of both host and the pathogen during an infectious process was not found. Using human cDNA microarray, the pathways affected by $S$. enterica serovar Typhimurium phoP gene within human monozygotic tissue culture cells was studied. The cells were infected with wild type or phoP-Salmonella mutant strains. Many common proinflammatory genes were 
induced by both strains, whereas differential expression between the strains was related to the induction of macrophage cell death. The mutant strain was defective in destroying macrophages but was capable of replicating intracellularly [35]. Rhee et al. [89] investigated the host response differences that occur in the small intestine in response to $S$. enterica Typhimurium infection in mice. The microarray based gene expression between an uninfected adult mice and pre weaned pups illustrated the difference in the expression of IFN gammaregulated genes. These genes are expressed at a higher level in a mature adult intestine than in pups, which clearly indicate susceptibility of pups and human infants to the pathogen.

Respiratory tract diseases are the major cause of economic loss in the poultry industry. Various respiratory tract viruses are among the most frequently found pathogens infecting commercial poultry. Despite enormous research into the pathogens of avian respiratory diseases, only few studies have addressed the responses of virally infected host tissues [71]. Differential gene expression of primary lymphoid organs of turkeys during infection with avian pneumovirus (APV) was analyzed using the microarray approach combined with subtractive hybridization [71]. Several host response genes in the thymus and bursa that likely act together were identified. The immune response transcripts for protein tyrosine phosphatase and B-cell receptor associated protein involved in $\mathrm{T}$ and B cell signal transduction were found to be upregulated. In addition to immune response genes, several genes responsible for a variety of cellular function, for example, heat shock and apoptosis induction genes were upregulated. In another study, response of chicken embryonic fibroblasts to infection with herpesvirus of turkeys (HVT) was studied. The HVT responding genes belonged to the immune system, signal transduction, transcription, and cytoskeleton [51]. Microarray analysis of the host response to Newcastle disease virus (NCDV) was evaluated. The transcript analysis showed suppression of IFN genes during early stages of infection as well as silencing of cytoskeleton proteins and suppres- sion of the thioredoxin gene. The comparative analysis of transcriptome response to closely related APV revealed unique patterns of host transcription in response to the members of the same phylogenetic tree [72]. An extended avian array previously used [71] was utilized in another study. Avian cDNA arrays comprised of chicken and turkey transcripts were generated from subtraction libraries derived from APV infected chicken embryo fibroblasts and bursa, and thymus tissues obtained from APV infected turkeys subtracted from their respective uninfected cultures and tissues [32]. The transcriptional profiles of lung tissue of infectious bronchitis virus (IBV) infected chicken embryos at various time periods were examined. A total of $27 \%$ genes exhibited altered expression of 2-fold or more that belong to several functional classes, such as kinases, interferon induced genes, chemokines, adhesion molecules, vesicular trafficking, extracellular matrix protein genes, translation, lysosomal, and ubiquitin related genes. The microarray analyses of avian host response to different viruses enabled a comparative analysis of different viral infections as well as of conserved and unique host responses.

In order to reach an inference about gene expression of the host in a disease process, it is first required to understand the expression of genes in normal tissues. To investigate normal physiological variation in gene expression in vivo in piglets, cDNA microarray was employed to measure expression levels in peripheral blood mononuclear cells from normal piglets. The results indicated significant variation in $1.6 \%$ genes involved in stress, immune response, and transcription. Piglets have been used as an animal model to study the effect of staphylococcal enterotoxin. Piglets are easy to handle, vital measurements can be done easily, and exhibit marked similarity to the human immune system. Therefore, piglets are being increasingly used as models to study many human diseases as well as human biological phenomenon. Hence, such studies of gene expression variations of animal models used to study human pathogens are important to interpret the final outcome of expression studies [47]. 
Another host response study to viral infection used swine cDNA microarray to examine transcriptome of swine macrophage to the African swine fever virus (ASFV). ASF is an important disease of swine with a mortality rate up to $100 \%$. The ASFV is a DNA virus that infects cells of the reticuloendothelial system. It is known that the multigene family 360 and 530 (MGF 360/530) of ASFV affects viral growth and virulence in pigs. The transcriptional response within macrophages infected by ASFV and MGF 360/530 deletion mutant was studied using swine cDNA array at various time intervals post infection [1]. The study revealed the suppression of the IFN response by ASFV MGF 360/530. The macrophage infected with the mutant strain showed IFN1 transcription, while cells harboring intact ASFV were devoid of any IFN1 activity. The inability of the mutant strain to suppress IFN response is likely an important factor in the attenuated, growth defective phenotype of the strain. The study highlights the biological significance of viral virulence within the macrophage.

Actinobacillus pleuropneumoniae causes contagious pleuropneumonia in pigs that relates to economic losses to the swine industry due to poor performance of pigs and mortality [64]. To investigate heritable differences in susceptibility to common infections in the swine population, microarray gene expression profiling was employed [70]. A cDNA microarray of immune cells and tissues of pigs was used to compare gene expression in peripheral blood leukocytes of two pigs exhibiting an extreme performance response to A. pleuropneumoniae infection. A novel approach based on the mixed-model and combined with mixtures of distributions was used for expression analyses, where interaction between the gene effect and immunological status was treated as a random effect. This study identified differentially expressed genes in susceptible and resistant pigs; the study suggests a powerful use of microarray experiments in segregating animals in livestock populations for breeding purposes.

A relatively larger number of host-microbe microarray studies have been conducted in bovine species as compared to other livestock species. The bovine DNA array work has primarily focused to interrogate normal physiology, pregnancy, lactation, and parturition [9, $17,94]$ mainly to understand cell physiology under various conditions, however, there are so far very few studies to examine host-pathogen interactions. Band et al. [8] developed a bovine microarray, which is now commercially available and has been used to study the response of bovine tissues to various pathogens. Immune response to bovine rotavirus and coronaviruses were studied using the intestinal "loop model". The data suggested differential expression of $\sim 13 \%$ genes by both RNA viruses. Since both the viruses lead to substantial destruction of mucosal epithelium with rapid alterations in the immune cell population, a primary bovine intestinal epithelial cell line was developed in order to limit the complexity of the organ for evaluation of rotavirus infection in vitro. The in vitro model provided confirmation of in vivo loop model observations; in addition, it tended to link expression of specific genes to mucosal epithelial cells [107]. Mastitis is a major cause of economic loss in the dairy industry and understanding the innate immunity of the mammary gland is important in devising measures to control the disease. Interactions of mastitis causing pathogens with mammary epithelial cells and in milk can be studied using DNA array platforms. Such studies could unravel susceptibility and resistant genes to mastitis and can assist in genetic selection of meritorious animals. A cDNA microarray was used to search signalling mechanisms of bovine mammary epithelial cells in response to $E$. coli LPS. The transcripts produced at $6 \mathrm{~h}$ post LPS stimulation were collected from control and infected epithelial cell cultures of Holstein cows. From the resulting data, the four significantly induced genes were selected for further analyses and validation [76].

The occurrence of many respiratory infections is linked to stress factors. To understand the role of stress in the host's susceptibility to disease, gene expression analyses of peripheral blood mononuclear cells (PBMC) of differently treated calves was done. A marked change in a number of genes was 
observed in calves that were infected with herpesvirus- 1 immediately after weaning than those pre-conditioned prior to infection [107]. Thus, for a global view of innate immune response to various conditions, microarray provides comprehensive information. Bovine leukemia virus (BLV) related to human T-cell leukemic virus type 1 causes tumor incidence in cattle, whereas in sheep, it causes leukemia, which provides a model for leukemia to understand oncogenesis. A cross-species ovine to human microarray approach was undertaken to study Tax (BLV) protein-mediated transcriptional changes in two sites of cultured ovine $\mathrm{B}$ cells. Tax is the major oncoprotein of BLV responsible for malignancy. Using cDNA spotted microarray comprised of human genes, a large number of differentially expressed genes were identified. The transcripts of genes included those of apoptosis, DNA transcription, cell cycle regulators, protooncogenes, and Tax responsive genes. Previously known genes linked with human neoplasia were highly expressed. The results of the study suggest regulation of a broad network of genes by Tax rather than single B-lineage species regulatory processes [54].

To understand both innate and adaptive immune responses, microarray based gene profiling of dendritic cells to pathogens and pathogen-associated molecules were studied previously [49]. The toll-like receptor (TLR) recognizes a variety of microbial pathogens and is an important component of innate immunity. The bovine microarray was used to identify common and unique TLR signaling pathways in immune response to LPS and CpG oligodinucleotides (ODN) in bovine monocytes [107]. The transcriptome revealed upregulation of $\sim 30$ common genes in the presence of LPS or CpG ODN, but the majority of differentially expressed genes were unique to each stimulus. The effect of cytopathogenic (cp) and non-cytopathogenic (ncp) bovine viral diarrhoea virus (BVDV) on bovine macrophages was examined focusing mainly on intracellular signaling molecules [105]. The study identified differentially expressed transcriptomes of macrophages infected with different strains of the pathogen. Such studies are useful in understanding differences in cellular response to variable pathotypes of species and in generating hypotheses for future research.

In another study, mechanisms of killing mycobacterial organisms by bovine macrophages were examined by employing bovine cDNA array. The gene expression of macrophages infected either by $M$. avium avium subsp. avium or by subsp. paratuberculosis indicated marked differences between macrophages phagocytizing the two strains. A lower expression of immune related genes was found in paratuberculosis infected macrophages than those harbouring avium subsp. Function assays confirmed higher acidification and greater apoptosis of $M$. avium subsp. avium infected cells for clearing infection [104]. This expression study indicated a complex interaction between the host and the mycobacterial species in progression of chronic disease. To understand the pathology of disease, the transcriptomes of the infected ileal tissues were compared with the uninfected ones using bovine total leukocyte cDNA array [3]. The highly expressed genes of tumor necrosis factor receptor associated protein 1, IL-1 $\alpha$, MCP-2, $\mathrm{N}$-cadherin, and beta 1 integrin were found in the infected tissues. The symptoms of disease are thought to be in part due to a very strong induction of IL-1 leading to toxicity. The study by Coussens et al. [28] demonstrated differential expression of numerous genes in PBMC from uninfected versus infected cattle. In another recent study, in order to identify some specific host signatures in response to M. paratuberculosis, cDNA microarrays were used to measure expression of over 1300 host genes. The transcript levels of at least 52 genes of M. paratuberculosis infected leukocytes were markedly different from the leukocytes obtained from control cows. The expressions of CD30 ligand and P-selectin genes were found to be consistently different in leukocytes isolated from infected and control cows of two different breeds [92].

To study early intramacrophage infection events of $B$. abortus, microarray analysis of macrophage transcriptome $4 \mathrm{~h}$ post infection was done. An increase in the transcripts of proinflammatory cytokines and chemokines 
Table III. Application of DNA arrays for studying technical advances.

\begin{tabular}{|c|c|c|c|}
\hline Type of array & Experimental design / purpose & Description & References \\
\hline $\begin{array}{l}\text { Cell membrane } \\
\text { array }\end{array}$ & $\begin{array}{c}\text { To study cell physiology, } \\
\text { ligand/receptor interactions }\end{array}$ & $\begin{array}{c}\text { Developed fluid cell membrane } \\
\text { arrays to investigate ligand/receptor binding } \\
\text { and cellular interactions }\end{array}$ & {$[110]$} \\
\hline Lectin array & $\begin{array}{l}\text { To examine glycoproteins } \\
\text { of pathogens }\end{array}$ & $\begin{array}{l}\text { Capable to differentiate } \\
\text { closely related species }\end{array}$ & [48] \\
\hline
\end{tabular}

that promote recruitment of antibacterial defences was evident. The transcription of host genes involved in apoptosis, cell cycling, and intracellular vesicular trafficking was inhibited. The results of this study suggest the trafficking of macrophages by Brucella is important for progressive infection and multiplication while inhibiting apoptotic pathways and innate immune mechanisms in parallel, thus permitting intracellular survival of the pathogen [38].

The genome wide transcriptional changes in the murine leukaemic monocyte macrophage cell line RAW 264.7 infected by $B$. anthracis were studied using DNA arrays [13]. Some genes specific to B. anthracis infection were identified among the differentially expressed genes during the intracellular stage of the infection, along with general immune response genes. The gene encoding ornithine decarboxylase was highly induced during the apoptotic stage; the enzyme tends to suppress apoptosis of macrophage cells. In this study, the transcriptional response to anthrax lethal toxin was found to inhibit the host inflammatory response.

The infectious process of most pathogens begins with the attachment and invasion of mucosal surfaces of the host. The studies described to date point towards regulated expression of many conserved as well as novel and unique immune response genes against various pathogens. For example, many intracellular pathogens, such as B. abortus [38], B. anthracis [13], Mycobacteria species tended to inhibit apoptosis of macrophages by inducing biomolecules that suppress apoptosis, by inhibition of intravesicular trafficking, while inducing the expression of proinflammatory cytokines, cytoskeleton proteins, signal transduction genes in common. Avian viruses were found to induce signal transduction genes, stress response, cytokine genes, and apoptosis genes, whereas NCDV of poultry produced a unique infection signature by inhibiting apoptosis through inhibition of thioredoxin, a mediator of apoptosis [72]. Further studies should be useful in segregating common conserved host gene expression against a group of pathogens and to distinguish responses unique for each pathogen. Such information could guide to identify the latent infection at an early stage for proper treatment and management of the disease. The analysis of gene expression patterns during infection is valuable in updating options for new detection and therapeutic targets.

\section{TECHNICAL ADVANCES}

The DNA microarray technique is evolving with refinements and has expanded applications in veterinary and biomedical fields. Microarray experiments generate large amounts of data and analysis of data of varied array experiments has necessitated the development of many analysis tools. More than fifty different commercial and free software are currently available [111]. In a recent study, gene expression data from $E$. coli grown under aerobic and anaerobic conditions were mapped onto the enzymatic reaction nodes of its metabolic network. Such a novel method of generating interactive information from the gene expression data of metabolic network enzymes is useful in extracting physiologically relevant information about the adaptation of an organism in a particular condition [55]. In addition, the microarray method has undergone technical refinements as well depending on what the researcher intends to use the array for. A hybrid multiplex microarray microsystem consisting of 32 individually addressable array 
reaction chambers was developed that could enable the use of multi channel pipettes for addition of up to eight samples simultaneously [53]. This miniature array could read the samples with equal sensitivity and specificity as a full size array. A novel DNA chip whose substrate is comprised of minute columnar array structure made of plastic was designed by Nagino et al. [73]. The chip is highly sensitive, up to 100-fold higher than the reference DNA chips, thereby offering the possibility of showing gene expression patterns with very small amounts of RNA (0.1-0.01 $\mu \mathrm{g}$ of total RNA) without amplification. Because of its high sensitivity, the chip might be useful in diagnostics and forensics.

Yamazaki et al. [110] provide another development in array technology (Tab. III). These researchers generated cell membrane microarray for performing high throughput testing. The membranes are physiological fluid, which could be used for studying cellular processes on a large scale. Above the membrane array solid substrate is a fluid supported lipid bilayer containing relevant biological molecules that enables the study of ligand/receptor binding and other cellular interactions. The utility of this biological array was demonstrated by examining multivalent binding of cholera toxin B subunit to the membrane ganglioside GM1.

A lectin microarray was developed to study glycoproteins of microorganisms. Glycosylation of bacterial cell structure is an important factor in symbiosis, pathogenesis, host-cell interactions, and immune evasion. The lectin array offers the possibility of examining bacterial glycans (Tab. III). The glycosylation patterns are distinct among closely related species and therefore are a means of fingerprinting bacteria [48].

\section{CONCLUSION}

The studies referenced in this paper indicate that the thoughtfully designed and efficiently conducted microarray experiment is an appropriate implementation of the principle of nucleic acid hybridization. Since it permits the profiling of expression of thousands of molecules in a single step, it helps in exam- ining the system as a whole. Most of the microarray studies documented so far have used model systems to define pathogenesis and the host cell response. Future refinements of the technique at procuring pure prokaryotic and host mRNA could help design more efficient in vivo methods to precisely understand hostpathogen interactions. Microarray technology has become a rapid and efficient method in clinical diagnostics, refined detection of genetic polymorphisms and gene transfers in pathogens. The molecular insights thus gained likely augment the understanding of pathogenesis, help in phylogenetic classification of microbes, drug development, and disease diagnosis.

Acknowledgements. Support for this research was provided by Agriculture and Agri-Food Canada.

\section{REFERENCES}

[1] Afonso C.L., Piccone M.E., Zaffuto K.M., Neilan J., Kutish G.F., Lu Z., Balinsky C.A., Gibb T.R., Bean T.J., Zsak B.L., Rock D.L., African swine fever virus multigene family 360 and 530 genes affect host interferon response, J. Virol. (2004) 78:1858-1864.

[2] Ahn S., Walt D.R., Detection of Salmonella spp. using microsphere-based, fiber optic DNA microarrays, Anal. Chem. (2005) 77:5041-5047.

[3] Aho A.D., McNulty A.M., Coussens P.M., Enhanced expression of interleukin-1 alpha and tumor necrosis factor-associated protein 1 in ileal tissues of cattle infected with Mycobacterium avium subsp. paratuberculosis, Infect. Immun. (2003) 71:6479-6486.

[4] Al-Khaldi S.F., Myers K.M., Rasooly A., Chizhikov V., Genotyping of Clostridium perfringens toxins using multiple oligonucleotide microarray hybridization, Mol. Cell. Probes (2004) 18:359-367.

[5] Amano M., Ohkusu K., Kusaba K., Ikeda H., Nagasawa Z., Aoki Y., Kawamura Y., Kobatake S., Tanaka T., Matsuura S., Ezaki T., Quantitative microarray-based DNA-DNA hybridization assay for measuring genetic distances among bacterial species and its application to the identification of family Enterobacteriaceae, Microbiol. Immunol. (2005) 49:255-263.

[6] Anjum M.F., Marooney C., Fookes M., Baker S., Dougan G., Ivens A., Woodward M.J., Identification of core and variable components of the Salmonella enterica subspecies I genome by microarray, Infect. Immun. (2005) 73:7894-7905.

[7] Bae J.W., Rhee S.K., Nam Y.D., Park Y.H., Generation of subspecies level-specific microbial diagnostic microarrays using genes amplified from subtractive suppression hybridization as microarray probes, Nucleic Acids Res. (2005) 33:e113. 
[8] Band M.R., Olmstead C., Everts R.E., Liu Z.L., Lewin H.A., A 3800 gene microarray for cattle functional genomics: comparison of gene expression in spleen, placenta, and brain, Anim. Biotechnol. (2002) 13:163-172.

[9] Bauersachs S., Blum H., Mallok S., Wenigerkind H., Rief S., Prelle K., Wolf E., Regulation of ipsilateral and contralateral bovine oviduct epithelial cell function in the postovulation period: a transcriptomics approach, Biol. Reprod. (2003) 68:1170-1177.

[10] Baxi M.K., Baxi S., Clavijo A., Burton K.M., Deregt D., Microarray-based detection and typing of foot-and-mouth disease virus, Vet. J. (2006) 172:473481.

[11] Behr M.A., Wilson M.A., Gill W.P., Salamon H., Schoolink G.K., Rane S., Small P.M., Comparative genomics of BCG vaccines by whole-genome DNA microarray, Science (1999) 284:1520-1523.

[12] Bekal S., Brousseau R., Masson L., Prefontaine G., Fairbrother J., Harel J., Rapid identification of Escherichia coli pathotypes by virulence gene detection with DNA microarrays, J. Clin. Microbiol. (2003) 41:2113-2125.

[13] Bergman N.H., Passalacqua K.D., Gaspard R., Shetron-Rama L.M., Quackenbush J., Hanna P.C., Murine macrophage transcriptional responses to Bacillus anthracis infection and intoxication, Infect. Immun. (2005) 73:1069-1080.

[14] Boyce J.D., Wilkie I., Harper M., Paustian M.L., Kapur V., Genomic scale analysis of Pasteurella multocida gene expression during growth within the natural chicken host, Infect. Immun. (2002) 70:6871-6879.

[15] Boyd E.F., Porwollik S., Blackmer F., McClelland M., Differences in gene content among Salmonella enterica serovar Typhi isolates, J. Clin. Microbiol. (2003) 41:3823-3828.

[16] Bryant P.A., Venter D., Robbins-Browne R., Curtis N., Chips with everything: DNA microarrays in infectious diseases, Lancet Infect. Dis. (2004) 4:100111.

[17] Burton J.L., Madsen S.A., Yao J., Sipkovsky S.S., Coussens P.M., An immunogenomics approach to understanding periparturient immunosuppression and mastitis susceptibility in dairy cows, Acta Vet. Scand. (2001) 42:407-424.

[18] Burton J.E., Oshota J., North E., Hudson M.J., Polyanskaya N., Brehm J., Lloyd G., Silman N.J., Development of a multipathogen oligonucleotide microarray for detection of Bacillus anthracis, Mol. Cell. Probes (2005) 19:349-357.

[19] Cai H.Y., Lu L., Muckle C.A., Prescott J.F., Chen S., Development of a novel protein microarray method for serotyping Salmonella enterica strains, J. Clin. Microbiol. (2005) 43:3427-3430.

[20] Call D.R., Bakko M.K., Krug M.J., Roberts M.C., Identifying antimicrobial resistance genes with DNA microarrays, Antimicrob. Agents Chemother. (2003) 47:3290-3295.

[21] Call D.R., Brockman F.J., Chandler D.P., Detecting and genotyping Escherichia coli O157:H7 using multiplexed PCR and nucleic acid microarrays, Int. J. Food Microbiol. (2001) 67:71-80.

[22] Call D.R., Kang M.S., Daniels J., Besser T.E., Assessing genetic diversity in plasmids from Escherichia coli and Salmonella enterica using a mixed-plasmid microarray, J. Appl. Microbiol. (2006) 100:15-28.

[23] Call D.R., Challenges and opportunities for pathogen detection using DNA microarrays, Crit. Rev. Microbiol. (2005) 31:91-99.

[24] Chan K., Baker S., Kim C.C., Detweiler C.S., Dougan G., Falkow S., Genomic comparison of Salmonella enterica serovars and Salmonella bongori by use of an S. enterica serovar Typhimurium DNA microarray, J. Bacteriol. (2003) 185:553-563.

[25] Chan K., Kim C.C., Falkow S., Microarray-based detection of Salmonella enterica serovar Typhimurium transposon mutants that cannot survive in macrophage and mice, Infect. Immun. (2005) 73:5438-5449.

[26] Chizhikov V., Rasooly A., Chumakov K., Levy D.D., Microarray analysis of microbial virulence factors, Appl. Environ. Microbiol. (2001) 67:3258-3263.

[27] Clements M.O., Eriksson S., Thompson A., Lucchini S., Hinton J.C.D., Normark S., Rhen M., Polynucleotide phosphorylase is a global regulator of virulence and persistency in Salmonella enterica, Proc. Natl. Acad. Sci. USA (2002) 99:8784-8789.

[28] Coussens P.M., Pudrith C.B., Skovgaard K., Ren X., Suchyta S.P., Stabel J.R., Heegaard P.M.H., Johne's disease in cattle is associated with enhanced expression of genes encoding IL-5, GATA-3, tissue inhibitors of matrix metalloproteinase 1 and 2, and factors promoting apoptosis in peripheral blood mononuclear cells, Vet. Immunol. Immunopathol. (2005) 105:221-234.

[29] Cummings C.A., Brinig M.M., Lepp P.W., van de Pas S., Relman D.A., Bordetella species are distinguished by patterns of substantial gene loss and host adaptation, J. Bacteriol. (2004) 186:1484-1492.

[30] Cummings C.A., Relman D.A., Using DNA microarrays to study host-microbe interactions, Emerg. Infect. Dis. (2000) 6:513-525.

[31] Dahan S., Knutton S., Shaw R.K., Crepin V.F., Dougan G., Frankel G., Transcriptome of enterohemorrhagic Escherichia coli O157 adhereing to eukaryotic plasma membranes, Infect. Immun. (2004) 72:5452-5459.

[32] Dar A., Munir S., Vishwanathan S., Manuja A., Griebel P., Tikko S., Townsend H., Potter A., Kapur V., Babiuk L.A., Transcriptional analysis of avian embryonic tissues following infection with avian infectious bronchitis virus, Virus Res. (2005) 110:41-55.

[33] Debouck C., Goodfellow P.N., DNA microarrays in drug discovery and development, Nat. Genet. (1999) 21:48-50.

[34] De Keersmaecker S.C., Marchal K., Verhoeven T.L., Engelen K., Vanderleyden J., Detweiler C.S., Microarray analysis and motif detection reveal new targets of the Salmonella enterica serovar Typhimurium HilA regulatory protein, including HilA itself, J. Bacteriol. (2005) 187:4381-4391. 
[35] Detweiler C.S., Cunanan D.B., Falkow S., Host microarray analysis reveals a role for the Salmonella response regulator $p h o P$ in human macrophage cell death, Proc. Natl. Acad. Sci. USA (2001) 8:58505855 .

[36] Diaz R., Siddiqi N., Rubin E.J., Detecting genetic variability among different Mycobacterium tuberculosis strains using DNA microarray technology, Tuberculosis (2006) 86:314-318.

[37] Dowd S.E., Ishizaki H., Microarray based comparison of two Escherichia coli O157:H7 lineages, BMC Microbiol. (2006) 15:30.

[38] Eskra L., Mathison A., Splitter G., Microarray analysis of mRNA levels from RAW264.7 macrophages infected with Brucella abortus, Infect. Immun. (2003) 71:1125-1133.

[39] Fadl A.A., Galindo C.L., Sha J., Klimpel G.R., Popov V.L., Chopra A.K., Global gene expression of a murein (Braun) lipoprotein mutant of Salmonella enterica Typhimurium by microarray analysis, Gene (2006) 374:121-127.

[40] Faucher S.P., Porwollik S., Dozois C.M., McClelland M., Daigle F., Transcriptome of Salmonella enterica serovar Typhi within macrophages revealed through selective capture of transcribed sequences, Proc. Natl. Acad. Sci. USA (2006) 103:1906-1911.

[41] Fitzgerald J.R., Sturdevant D.E., Mackie S.M., Gill S.R., Musser J.M., Evolutionary genomics of Staphylococcus aureus: Insights into the origin of methicillin-resistant strains and the toxic shock syndrome epidemic, Proc. Natl. Acad. Sci. USA (2001) 98:8821-8826.

[42] Frye J.G., Jesse T., Long F., Rondeau G., Porwollik S., McClelland M., Jackson C.R., Englen M., Fedorka-Cray P.J., DNA microarray detection of antimicrobial resistance genes in diverse bacteria, Int. J. Antimicrob. Agents (2006) 27:138-151.

[43] Fu L.M., Exploring drug action on Mycobacterium tuberculosis using affymetrix oligonucleotide genechips, Tuberculosis (2006) 86:134-143.

[44] Garaizar J., Porwollik S., Echeita A., Rementeria A., Herrera S., Wong R.M., Frye J., Usera M.A., McClelland M., DNA microarray-based typing of an atypical monophasic Salmonella enterica serovar, J. Clin. Microbiol. (2002) 40:2074-2078.

[45] Garrido P., Blanco M., Moreno-Paz M., Briones C., Dahbi G., Blanco J., Blanco J., Parro V., STECEPEC oligonucleotide microarray: a new tool for typing genetic variants of the LEE pathogenicity island of human and animal Shiga toxin-producing Escherichia coli (STEC) and enteropathogenic E. coli (EPEC) strains, Clin. Chem. (2006) 52:192-201.

[46] Goldschmidt M.C., The use of biosensor and microarray techniques in the rapid detection and identification of Salmonellae, J. AOAC Int. (2006) 89:530 537.

[47] Hammamieh R., Bi S., Mani S., Charaborty N., Mendis C., Das R., Jett M., Genetic variations in peripheral blood mononuclear cells in piglets used as an animal model for staphylococcal enterotoxin exposures, OMICS (2003) 7:401-409.

[48] Hsu K.L., Pilobello K.T., Mahal L.K., Analyzing the dynamic bacterial glycome with a lectin microarray approach, Nat. Chem. Biol. (2006) 2:153-157.

[49] Huang Q., Liu D., Majewski P., Schulte L.C., Korn J.M., Young R.A., Lander E.S., Hacohen N., The plasticity of dendritic cell responses to pathogens and their components, Science (2001) 294:870-875.

[50] Kakinuma K., Fukushima M., Kawaguchi R., Detection and identification of Escherichia coli, Shigella, and Salmonella by microarrays using the gyrB gene, Biotechnol. Bioeng. (2003) 83:721-728.

[51] Karaca G., Anobile J., Downs D., Burnside J., Schmidt C.J., Herpesvirus of turkeys: microarray analysis of host gene response to infection, Virology (2004) 318:102-111.

[52] Kato-Maeda M., Gao Q., Small P.M., Microarray analysis of pathogens and their interaction with hosts, Cell. Microbiol. (2001) 3:713-719.

[53] Keramas G., Perozziello G., Geschke O., Christensen C.B., Development of a multiplex microarray microsystem, Lab Chip (2004) 4:152-158. [54] Klener P., Szynal M., Cleuter Y., Merimi M., Duvillier H., Lallemand F., Bagnis C., Griebel P., Sotiriou C., Burny A., Martiat P., van den Broeke A., Insights into gene expression changes impacting B-cell transformation: cross-species microarray analysis of bovine leukemia virus tax-responsive genes in ovine B cells, J. Virol. (2006) 80:1922-1938.

[55] Konig R., Schramm G., Oswald M., Seitz H., Sager S., Zapatka M., Reinelt G., Eils R., Discovering functional gene expression patterns in the metabolic network of Escherichia coli with wavelets transforms, BMC Bioinformatics (2006) 8:119.

[56] Korczak B., Frey J., Schrenzel J., Pluschke G., Pfister R., Ehricht R., Kuhnert P., Use of diagnostic microarrays for determination of virulence gene patterns of Escherichia coli K1, a major cause of neonatal meningitis, J. Clin. Microbiol. (2005) 43:1024-1031.

[57] Kostic T., Weilharter A., Sessitsch A., Bodrossy L., High-sensitivity, polymerase chain reaction-free detection of microorganisms and their functional genes using 70-mer oligonucleotide diagnostic microarray, Anal. Biochem. (2005) 346:333-335.

[58] Kostrzynska M., Bachand A., Application of DNA microarray technology for detection, identification, and characterization of food-borne pathogens, Can. J. Microbiol. (2006) 52:1-8.

[59] Lawhon S.D., Frye J.G., Suyemoto M., Porwollik S., McClelland M., Altier C., Global regulation by CsrA in Salmonella typhimurium, Mol. Microbiol. (2003) 48:1633-1645.

[60] Lawley T.D., Chan K., Thompson L.J., Kim C.C., Govoni G.R., Monack D.M., Genome-wide screen for Salmonella genes required for long-term systemic infection of the mouse, PLoS Pathog. (2006) 2(2):e11.

[61] Lee L.J., Barrett J.A., Poole R.K., Genome-wide transcriptional response of chemostat-cultured Escherichia coli to zinc, J. Bacteriol. (2005) 187:1124-1134. 
[62] Lin Baochuan L., Wang Z., Vora G.J., Thornton J.A., Schnur J.M., Thach D.C., Blaney K.M., Ligler A.G., Malanoski A.P., Santiago J., Walter E.A., Agan B.K., Metzgar D., Seto D., Daum L.T., Kruzelock R., Rowley R.K., Hanson E.H., Tibbetts C., Stenger D.A., Broad-spectrum respiratory tract pathogen identification using resequencng DNA microarrays, Genome Res. (2006) 16:527-535.

[63] Liu Y.C., Huang G.S., Wu M.C., Hong M.Y., Hsiung K.P., Detection of foot and mouth disease and porcine reproductive and respiratory syndrome viral genes using microarray chip, Vet. Res. Commun. (2006) 30:191-204.

[64] MacInnes J.I., Lally E.T., The genus Actinobacillus, in: Dworkin W. et al. (Eds.), The Prokaryotes: An evolving electronic resource for the microbiological community, 3rd ed., Springer-Verlag, New York, 2004.

[65] Madsen M.L., Nettleton D., Thacker E.L., Edwards R., Minion F.C., Transcriptional profiling of Mycoplasma hyopneumoniae during heat shock using microarrays, Infect. Immun. (2006) 74:160-166.

[66] Malone A.S., Chung Y.K., Yousef A.E., Genes of Escherichia coli $\mathrm{O} 157: \mathrm{H} 7$ that are involved in highpressure resistance, Appl. Environ. Microbiol. (2006) 72:2661-2671.

[67] Marsh I.B., Bannantine J.P., Paustian M.L., Tizard M.L., Kapur V., Whittington R.J., Genomic comparison of Mycobacterium avium subsp. paratuberculosis sheep and cattle strains by microarray hybridization, J. Bacteriol. (2006) 188:2290-2293.

[68] Melnikow E., Dornan S., Sargent C., Dusko M., Evans G., Gunkel N., Selzer P.M., Ullrich H.J., Microarray analysis of Haemophilus parasuis gene expression under in vitro growth conditions mimicking the in vivo environment, Vet. Microbiol. (2005) 110:255-263.

[69] Morales C.A., Porwollik S., Frye J.G., Kinde H., McClelland M., Guard-Bouldin J., Correlation of phenotype with the genotype of egg-contaminating Salmonella enterica serovar enteritidis, Appl. Environ. Microbiol. (2005) 71:4388-4399.

[70] Moser R.J., Reverter A., Kerr C.A., Beh K.J., Lehnert S.A., A mixed-model approach for the analysis of cDNA microarray gene expression data from extreme-performing pigs after infection with Actinobacillus pleuropneumoniae, J. Anim. Sci. (2004) 82:1261-1271.

[71] Munir S., Kapur V., Transcriptional analysis of the response of poultry species to respiratory pathogens, Poult. Sci. (2003) 82:885-892.

[72] Munir S., Sharma J.M., Kapur V., Transcriptional response of avian cells to infection with Newcastle disease virus, Virus Res. (2005) 107:103-108.

[73] Nagino K., Nomura O., Takii Y., Myomoto A., Ichikawa M., Nakamura F., Higasa M., Akiyama H., Nobumasa H., Shiojima S., Tsujimoto G., Ultrasensitive DNA chip: Gene expression profile analysis without RNA amplification, J. Biochem. (2006) 139:697-703.
[74] Oshima T., Wada C., Kawagoe Y., Ara T., Maeda M., Masuda Y., Hiraga S., Mori H., Genomewide analysis of deoxyadenosine methyltransferasemediated control of gene expression in Escherichia coli, Mol. Microbiol. (2002) 45:673-695.

[75] Overton T.W., Griffiths L., Patel M.D., Hobman J.L., Penn C.W., Cole J.A., Constantinidou C., Microarray analysis of gene regulation by oxygen, nitrate, nitrite, FNR, NarL, and NarP during anaerobic growth of Escherichia coli: new insights into microbial physiology, Biochem. Soc. Trans. (2006) 34:104-107.

[76] Pareek R., Wellntiz O., van Dorp R., Burton J., Kerr D., Immunorelevant gene expression in LPSchallenged bovine mammary epithelial cells, J. Appl. Genet. (2005) 46:171-177.

[77] Patel D., Danelishvili L., Yamazaki Y., Alonso M., Paustian M.L., Bannantine J.P., Meunier-Goddik L., Bermudez L.E., The ability of Mycobacterium avium subsp. paratuberculosis to enter bovine epithelial cells is influenced by preexposure to a hyperosmolar environment and intracellular passage in bovine mammary epithelial cells, Infect. Immun. (2006) 74:2849-2855.

[78] Paustian M.L., May B.J., Kapur V., Pasteurella multocida gene expression in response to iron limitation, Infect. Immun. (2001) 69:4109-4115.

[79] Pelludat C., Prager R., Tschape H., Rabsch W., Schuchhardt J., Hardt W.D., Pilot study to evaluate microarray hybridization as a tool for Salmonella enterica serovar Typhimurium strain differentiation, J. Clin. Microbiol. (2005) 43:4092-4106.

[80] Perreten V., Vorlet-Fawer L., Slickers P., Ehricht R., Kuhnert P., Frey J., Microarray-based detection of 90 antibiotic resistance genes of gram-positive bacteria, J. Clin. Microbiol. (2005) 43:2291-2302.

[81] Porwollik S., Boyd E.F., Choy C., Cheng P., Florea L., Proctor E., McClelland M., Characterization of Salmonella enterica subspecies I genovars by use of microarrays, J. Bacteriol. (2004) 186:5883-5898.

[82] Porwollik S., Frye J., Florea L.D., Blackmer F., McClelland M., A non-redundant microarray of genes for two related bacteria, Nucleic Acids Res. (2003) 31:1869-1876.

[83] Porwollik S., Santiviago C.A., Cheng P., Florea L., McClelland M., Differences in gene content between Salmonella enterica serovar Enteritidis isolates and comparison to closely related serovars Gallinarum and Dublin, J. Bacteriol. (2005) 187:6545-6555.

[84] Porwollik S., Wong R.M., McClelland M., Evolutionary genomics of Salmonella: gene acquisitions revealed by microarray analysis, Proc. Natl. Acad. Sci. USA (2002) 99:8956-8961.

[85] Rahman M.T., Parreira V., Prescott J.F., In vitro and intra-macrophage gene expression by Rhodococcus equi strain 103, Vet. Microbiol. (2005) 110:131-140.

[86] Rajashekara G., Glasner J.D., Glover D.A., Splitter G.A., Comparative whole-genome hybridization reveals genomic islands in Brucella species, J. Bacteriol. (2004) 186:5040-5051. 
[87] Reen F.J., Boyd E.F., Porwollik S., Murphy B.P., Gilroy D., Fanning S., McClelland M., Genomic comparisons of Salmonella enterica serovar Dublin, Agona, and Typhimurium strains isolated from milk filters and bovine samples from Ireland, using a Salmonella microarray, Appl. Environ. Microbiol. (2005) 71:1616-1625.

[88] Revel A.T., Talaat A.M., Norgard M.V., DNA microarray analysis of differential gene expression in Borrelia burgdorferi, the Lyme disease spirochete, Proc. Natl. Acad. Sci. USA (2002) 99:1562-1567.

[89] Rhee S.J., Walker W.A., Cherayil B.J., Developmentally regulated intestinal expression of IFN-gamma and its target genes and the agespecific response to enteric Salmonella infection, J. Immunol. (2005) 15:1127-1136.

[90] Schembri M.A., Ussery D.W., Workman C., Hasman H., Klemm P., DNA microarray analysis of fim mutations in Escherichia coli, Mol. Genet. Genomics (2002) 267:721-729.

[91] Sergeev N., Distler M., Courtney S., AlKhaldi S.F., Volokhov D., Chizhikov V., Rasooly A., Multipathogen oligonucleotide microarray for environmental and biodefense applications, Biosens. Bioelectron. (2004) 20:684-698.

[92] Skovgaard K., Grell S.N., Heegaard P.M., Jungersen G., Pudrith C.B., Coussens P.M., Differential expression of genes encoding CD30L and P-selectin in cattle with Johne's disease: progress toward a diagnostic gene expression signature, Vet. Immunol. Immunopathol. (2006) 112:210-224.

[93] Staudinger B.J., Oberdoerster M.A., Lewis P.J., Rosen H., mRNA expression profiles for Escherichia coli ingested by normal and phagocyte oxidasedeficient human neutrophils, J. Clin. Invest. (2002) 110:1151-1163.

[94] Suchyta S.P., Sipkovsky S., Halgren R.G., Kruska R., Elftman M., Weber-Nielsen M., Vandehaar M.J., Xiao L., Tempelman R.J., Coussens P.M., Bovine mammary gene expression profiling using cDNA microarray enhanced mammary-specific transcripts, Physiol. Genomics (2003) 161:8-18.

[95] Tani T.H., Khodursky A., Blumenthal R.M., Brown P.O., Matthews R.G., Adaptation to famine: A family of stationary-phase genes revealed by microarray analysis, Proc. Natl. Acad. Sci. USA (2002) 99:13471-13476.

[96] Thirumalapura N.R., Morton R.J., Ramachandran A., Malayer J.R., Lipopolysaccharide microarrays for the detection of antibodies, J. Immunol. Methods (2005) 298:73-81.

[97] Tobler N.E., Pfunder M., Herzog K., Frey J.E., Altwegg M., Rapid detection and species identification of Mycobacterium spp. using real-time PCR and DNAmicroarray, J. Microbiol. Methods (2005) 66:116-124.

[98] Tong X., Campbell J.W., Balazsi G., Kay K.A., Wanner B.L., Gerdes S.Y., Oltvai Z.N., Genomescale identification of conditionally essential genes of E. coli by DNA microarrays, Biochem. Biophys. Res. Commun. (2004) 322:347-354.
[99] Van Hoek A.H., Scholtens I.M., Cloeckaert A., Aarts H.J., Detection of antibiotic resistance genes in different Salmonella serovars by oligonucleotide microarray analysis, J. Microbiol. Methods (2005) 62:13-23.

[100] Van Ijperen C., Kuhnert P., Frey J., Clewley J.P., Virulence typing of Escherichia coli using microarrays, Mol. Cell. Probes (2002) 16:371-378.

[101] Wang D., Coscoy L., Zylberberg M., Avila P.C., Boushey H.A., Ganem D., DeRisi J.L., Microarraybased detection and genotyping of viral pathogens, Proc. Natl. Acad. Sci. USA (2002) 99:15687-15692.

[102] Wang D., Urisman A., Liu Y.-T., Springer M., Ksiazek T.G., Erdman D.D., Mardis E.R., Hickenbotham M., Magrini V., Eldred J., Latreille J.P., Wilson R.K., Ganem D., DeRisi J.L., Viral discovery and sequence recovery using DNA microarrays, PLoS Biol. (2003) 1:257-260.

[103] Wang Q., Frye J.G., McClelland M., Harshey R.M., Gene expression patterns during swarming in Salmonella typhimurium: genes specific to surface growth and putative new motility and pathogenicity genes, Mol. Microbiol. (2004) 52:169-187.

[104] Weiss D.J., Evanson O.A., Deng M., Abrahamsen M.S., Sequential patterns of gene expression by bovine monocyte-derived macrophages associated with ingestion of mycobacterial organisms, Microb. Pathog. (2004) 37:215-224.

[105] Werling D., Ruryk A., Heaney J., Moeller E., Brownlie J., Ability to differentiate between cp and ncp BVDV by microarrays: towards an application in clinical veterinary medicine? Vet. Immunol. Immunopathol. (2005) 108:157-164.

[106] Willse A., Straub T.M., Wunschel S.C., Small J.A., Call D.R., Daly D.S., Chandler D.P., Quantitative oligonucleotide microarray fingerprinting of Salmonella enterica isolates, Nucleic Acids Res. (2004) 32:1848-1856.

[107] Wilson H.L., Aich P., Roche F.M., Jala S., Hodgson P.D., Brinkman F.S.L., Potter A., Babiuk L.A., Griebel P.J., Molecular analyses of disease pathogenesis: application of bovine microarrays, Vet. Immunol. Immunopathol. (2005) 105:227-287.

[108] Wilson W.J., Strout C.L., DeSantis T.Z., Stilwell J.L., Carrano A.V., Andersen G.L., Sequence-specific identification of 18 pathogenic microorganisms using microarray technology, Mol. Cell. Probes (2002) 16:119-127.

[109] Wu C.F., Valdes J.J., Bentley W.E., Sekowski J.W., DNA microarray for discrimination between pathogenic O157:H7 EDL933 and non-pathogenic Escherichia coli strains, Biosens. Biochem. (2003) 30:1-8.

[110] Yamazaki V., Sirenko O., Schafer R.J., Nguyen L., Gutsmann T., Brade L., Groves J.T., Cell membrane array fabrication and assay technology, BMC Biotechnol. (2005) 16:18.

[111] Zimmer D.P., Paliy O., Thomas B., Gyaneshwar P., Kustu S., Genome image programs: Visualization and interpretation of Escherichia coli microarray experiments, Genetics (2004) 167:2111-2119. 